\title{
Urban Farming Using Upcycling Technique of Brassica rapa L. Cv (Pechay Tagalog) in Ermita, Manila, Philippines
}

\author{
Alma E Nacua ${ }^{1,2 *}$, Ma Cristina R Macer $^{2}$ and Allen Belle M Pascual ${ }^{2}$ \\ ${ }^{1}$ Urban Biodiversity Laboratory, Philippines \\ ${ }^{2}$ Graduate School-University of the East, Philippines
}

ISSN: 2637-7659

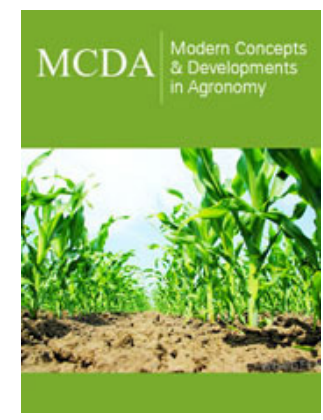

*Corresponding author: Alma E Nacua, Urban Biodiversity Laboratory, Philippines

Submission: 海 May 17, 2019

Published: 侮 May 28, 2019

Volume 4 - Issue 2

How to cite this article: Alma $\mathrm{E} \mathrm{N}$, Ma Cristina R M, Allen B M P. Urban Farming Using Upcycling Technique of Brassica rapa L. Cv (Pechay Tagalog) in Ermita, Manila, Philippines. Mod Concep Dev Agrono.4(3). MCDA.000587.2019.

DOI: 10.31031/MCDA.2019.04.000587

Copyright@ Alma E Nacua, This article is distributed under the terms of the Creative Commons Attribution 4.0 International License, which permits unrestricted use and redistribution provided that the original author and source are credited.

\begin{abstract}
In Manila, vegetables are extremely overpriced especially due to various reasons such as overshooting of gas price, high demand on peak seasons, drought, flood and when plants are infested with plague. When people prepare food in the kitchen, loads of vegetable parts such as peels, unused leaves, roots, and stem go in the trash bin as wastes, specifically Pechay. They cut the petiole with leaves and discarded the stem without realizing it can be re-planted (upcycled). The aim of this paper was to observe Pechay stem grow in a loam soil planted in used (recycled) fruit Styrofoam box and to upcycle the Pechay stem and to observed other signs and symptoms of infection. The experimental design method was used. The controlled variable was Pechay seed grown on the same type of container with loam soil. Out of 180 Pechay stems planted 128 survived with a 71\% survival growth for Pechay grown from the stem while $98 \%$ survival rate of Pechay grown from seeds. Pechay stem gowned in a loam soil.
\end{abstract}

KeyWords: Recycling; Upcycling

\section{Introduction}

Increasing population throughout the Philippines leads most of the Filipino scientists to find ways to mitigate issues concerning scarcity in food. Overpopulation leads to competition for the same source of food. In addition to this, in the Philippines when the supply for a particular source of food is low due to drought, flood, catastrophe and even plague the cost or price for the specific food becomes higher, leading to few number of Filipinos could only avail nutritive type of foods. Therefore, those at the urban poor sector are the least to avail a high, quality and nutritive value of food. More worst they only get food that is within their limited budget. Urban farming or gardening is one of the best tool to equip Filipinos against low nutritive type of food due to overshooting of prices. In urban farming, Filipinos are required to design their backyard or their available spaces in their house to construct a simple farm or garden. After quite some time, they can eventually harvest the fruits of their labour as their own source of food. Into this regard, Filipinos are ensured on the safety of the food that they harvested. Brassica rapa L. Cv commonly called as Pechay and is popularly known as vegetable in Manila, Philippines. Pechay is a leafy, shallow-rooted, cool-season crop but can stand higher temperatures given it is exposed to enough moisture. [1]. It is an erect, biennial herb, cultivated as an annual about $15-30 \mathrm{~cm}$ tall in vegetative stage. The leaves are ovate, spirally and widely spread arranged. The petioles are enlarged and growing vertically forming a sub cylindrical bundle. The inflorescence is a raceme with pale yellow flowers. Plant body consist of leaves, petiole, stem and roots. It is known as one of the oldest green vegetables in Asia. Therefore, Pechay plays an important role in the Philippine economy as well as in the nutrition of the Filipino people. Pechay is known for its nutritional value. In a serving of Pechay it contains calcium for strong bones, phosphorus for bone formation, digestion, excretion, and hormonal balance, potassium for muscle control, regulating blood pressure and preventing hypertension, as well as vitamin A for promoting growth, reproduction, and improvising vision and provides fiber for good digestion. It keeps your digestive system healthy, promotes healthy blood sugar and cholesterol and helps keep the blood pressure on an even keel [2].

When cooked, it has a sturdy fibrous leaf. Leaves can be eaten raw because of high nutritional value. In the Philippines it is usually added in the soups or beef stews, some cook it with fish sardines and sauté it with soy sauce, garlic, onions and tomatoes served with steamed 
rice. In Manila, due to scarcity of food supply during calamity, it was observed that prices of vegetables are overpriced. The low-income earner is directly affected, due to this they opt to buy low cost vegetables such as Pechay. It was a common practice that, when people prepare food in the kitchen, loads of vegetable waste go in the trash bin. Same in the market, vendors get rid the discarded vegetable wastes such as plant leaves, roots and stems. Specifically, on the case of Pechay, they cut the petiole with leaves and discarded the stem but does not realize it can be re-planted (upcycled).
Upcycling is often considered as a process in which waste materials are converted into something of higher value and/or quality in their second life. [3]. On this report study, we are looking forward on the effectivity of upcycling technique on Brassica rapa stems, because often the stems go directly to the garbage bin. On Figure 1, the first thing that humans do on wastes is to avoid it followed by reduce, reuse and recycle. Which is true nowadays, humans tend to use reusable plastic bag to avoid usage of plastics in supermarkets.

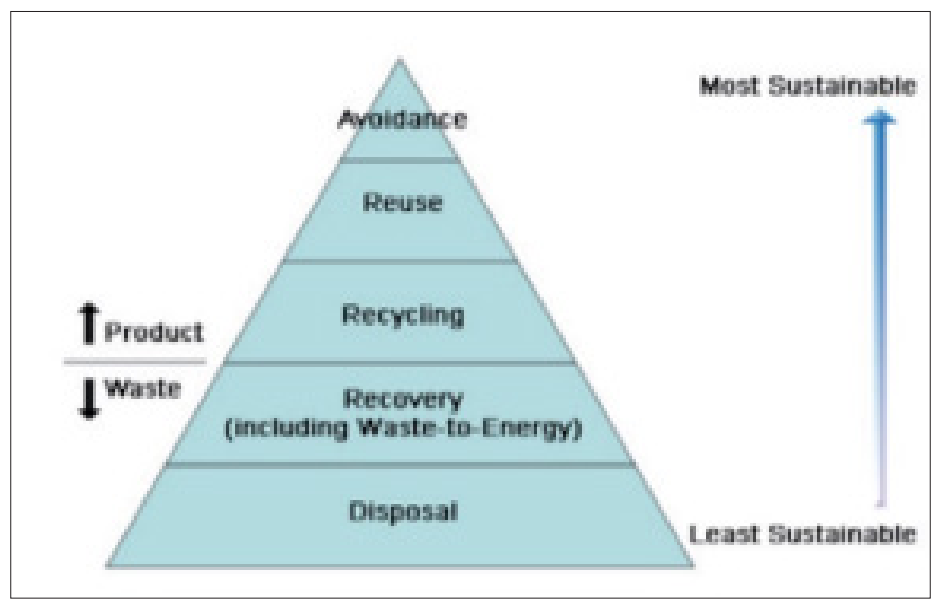

Figure 1: Waste Hierarchy Pyramid. EU.PNG. Online; accessed, 2015-04-30.

The waste can be termed as upcycled once its value is more than that of the original product. [4]. Once materials are being used and consumed by humans part of it will be considered as waste. Since, we could not return the used materials' original economic value, modern methods and techniques are being implemented to make the used materials of high economic value or important again. Thus, upcycling is of greater importance nowadays due to increasing socio economic demands for raw materials with respect to increasing human's basic needs. This research was an output in a Science technology and Society course of Universidad de Manila for first semester School year 2018-19. Upcycling was a process of transforming by- products, waste materials into a new product for a better purpose. It was in the intention of this study to educate students and to pass on this learning experience to their families and respective communities. In General, students of UDM are from the middle-class family, some of them came from a poor family from a depressed area of Manila. Many lives by hand to hand existence to provide food on the table and sending their children to school even more difficult. There were few families belong to an Informal settler of Manila were the average house was about 3 squares meters. Having no extra land to do urban farming was next to impossible but with the used of recyclable container for gardening can be an alternative. Almost any vegetable that will grow in a typical backyard garden will also do well as a container-grown plan. [5]. Urban farming technique for example, Upcycling Pechay can grow vegetable in a small space or even in a small container provided with soil and regular watering. Pechay for example brought nutritious food for local communities and provides health benefits. It also reduc- es obesity, diabetes, and heart ailments. Gardening is also a good exercise and developed diligence, patience, discipline to grow and harvest vegetable of their own. The virtue of sharing their harvested vegetable to others too.

\section{Aim of the Study}

Observe the growth of upcycled Pechay stem in a loam soil planted in recycled fruit Styrofoam box and to document traces of infection in the Pechay leaves.

\section{Material and Methods}

This was an example of a simple Experimental method designed. A controlled observation was used to compare the growth of Pechay seeds to the experimented upcycled Pechay stems. The research compared the survival rate of Pechay seed and upcycled Pechay stem. The morphological characteristic growth of Pechay were noted. The observation period covered for 2 months from September 1, 2018 to October 30, 2018. A research output of the students of Universidad de Manila under Science Technology and Society, for one semester equivalent to five (5) months an Outcome Based Education.

\section{Procedure}

There were 50 used empty fruit box made of Styrofoam with 22.4 inches' length and 14.5 inches' width and 4.2 inches' depth with holes for passageway of excess water (Figure 2). It was filled with loam soil were seeds are planted. Watering of Pechay were 
done early in the morning to prevent sunscald. Fertilizer and pesticide were not included. On Figure 3 found the controlled observation Pechay seeds. On the other empty fruit boxes found on Figure 4, Upcycled Pechay stem planted on loam soil. They were observed each day for a growth characteristic: growing leaves and increasing height of plants (Table 1). The observable growing leaves coming out for the stem and increasing height of petiole each day were measured in mm. After 14 days, the height of the plant increase and the foliage developed found on Figure 5.

Table 1: Tabulated data of upcycled pechay stem.

\begin{tabular}{|c|c|c|c|}
\hline Groups & Number of Pechay Stem & Number of Pechay Stem Survived & Percent of Survival \\
\hline PA 12 & 20 & 18 & $90 \%$ \\
\hline HRDM 11 & 20 & 2 & $10 \%$ \\
\hline MM 13 & 20 & 5 & $25 \%$ \\
\hline ED 14 & 20 & 15 & $40 \%$ \\
\hline ECO 11 & 20 & 20 & $75 \%$ \\
\hline ECO 12 & 20 & 20 & $100 \%$ \\
\hline BAC 12 & 20 & 20 & $100 \%$ \\
\hline BAC 11 & 20 & 20 & $100 \%$ \\
\hline BEN 11 & 20 & 128 & $100 \%$ \\
\hline Total & 180 & 8 & $71 \%$ \\
\hline
\end{tabular}

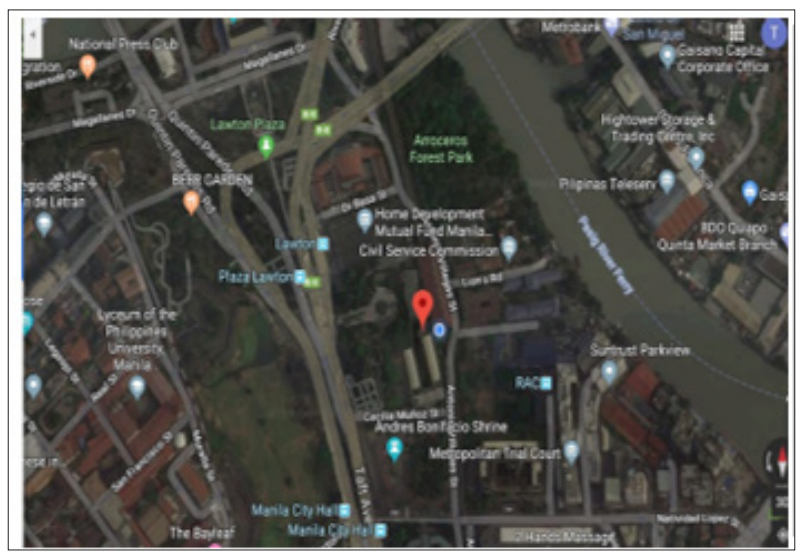

(A)oggle earth Map

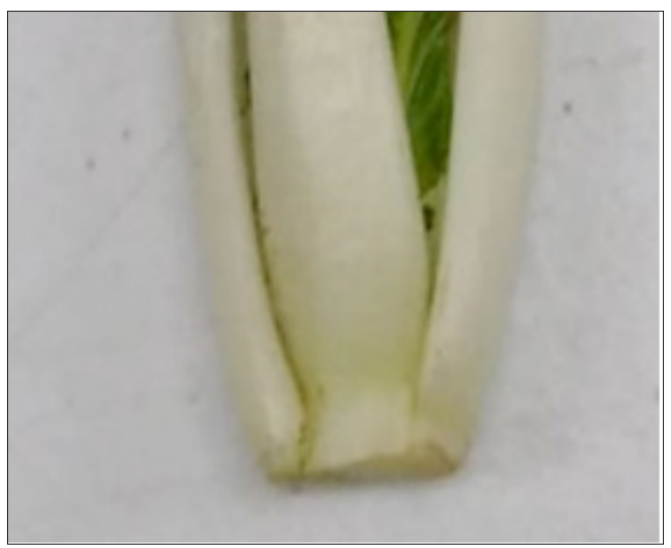

(B) Pechay stem cuttings

Figure 2: (A) Geographical satellite view of the study site, Universidad de Manila (UDM) at the Second-floor building of the Biodiversity laboratory, with the coordinates of Latitude 14.591910 and a longitude 12.981629 .

(B) Pechay stem cutting used for upcyling. 


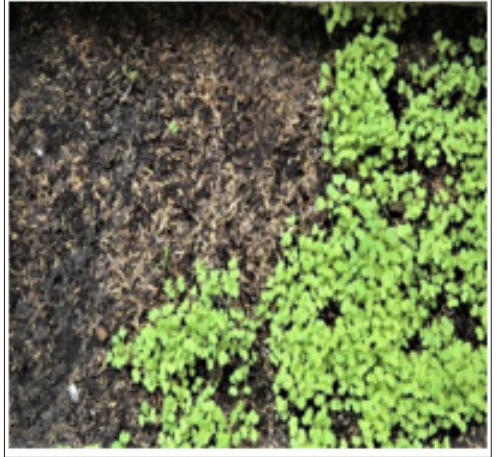

Figure 3: Control variable (Pechay Seed).

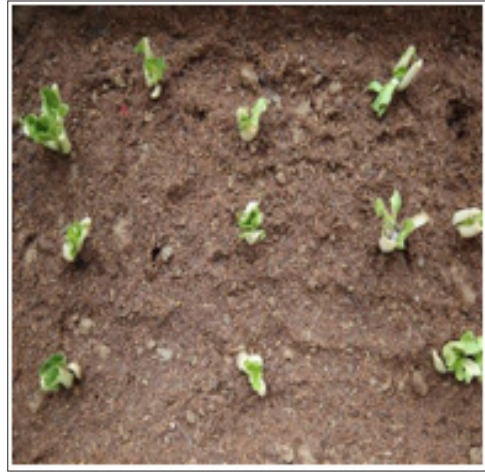

Figure 4: Pechay stem.

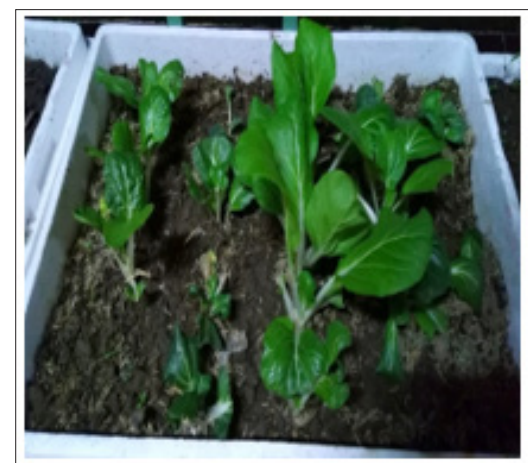

Figure 5: Full grown upcycled Pechay Stem.

On Figure 6, it shows the controlled grown Pechay though the conventional seed planting. Likewise, it also shows the growth parts of Pechay; roots, stem and leaves. Leaf buds came out 3-4 days after it was planted. Height of plants reached up to $127 \mathrm{~mm}$, and $12.7 \mathrm{~mm}$ size of the leaf blade from midrib to the margin were observed in 2weeks. While on Figure 7, the experimented upcycled stem of Pechay. It shows the growth development in Pechay stem. Within 3 -4days, leaves came out. Height reached to $254 \mathrm{~mm}$ from roots to leaf. Size of the leaf blade were measured to $76.6 \mathrm{~mm}$ from midrib to margin. On Figure 8, there is an observed V shaped suspected infection found on the leaf of the Pechay both on the controlled and experimented Pechay. While on Figure 9, there is a spotted infected leaf on both controlled and experimented Pechay. This table shows the data collected of grown Pechay stem. Out of 180 planted Pechay stem, there were only 128 survived and with $71 \%$ survival rate in a loam soil planted in a recycled Styrofoam at the second floor of the corridor of Universidad de Manila (UDM). Minimal Sunlight and a few drops of rain from September to October 2018. Results show on Figure 7 a successful full grown upcycled Pechay stem. It was shown in Table 2, data gathered from Pechay seeds survived planted in loam soil for 60 days. Out of 180 seeds planted, there were 177plants developed into a full-grown Pechay and having 98.33\% survival rate. They were also planted in a loam soil in a recycled Styrofoam placed along the corridor of UDM with minimal sunlight and water. Figure 6 shows the Pechay plant planted though the seed planting' with a healthy full-grown leaf. Comparing the survival rate of Pechay stem and Pechay seeds cultivated in the corridor of UDM, these 2 samples were found successful. Both of the samples able to adopt to the same environment; loam soil, type of water, recycled fruit Styrofoam box. The possibility of growth and development of Pechay are successful, however some samples of Upcycled Pechay stems of HRDM, MM, Ed and Eco were not very successful compare for the others groups of students (Table 3). It was because of some protocol that was not strictly followed.

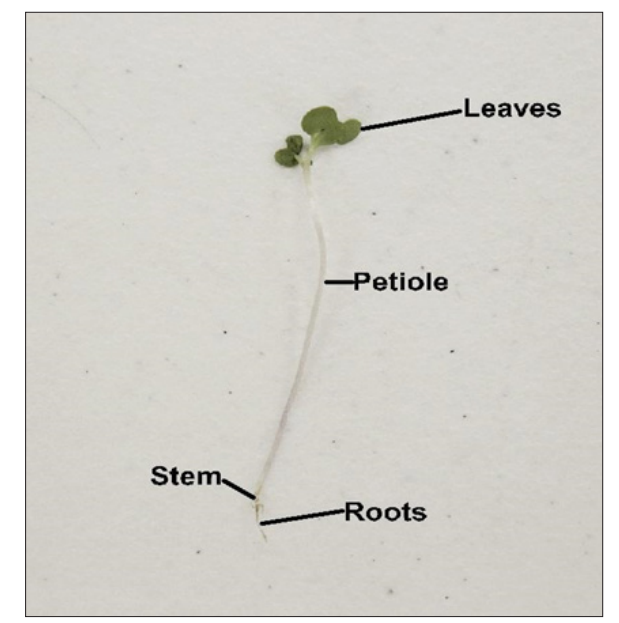

Figure 6: Pechay with its growth parts using conventional way of plantings seeds.

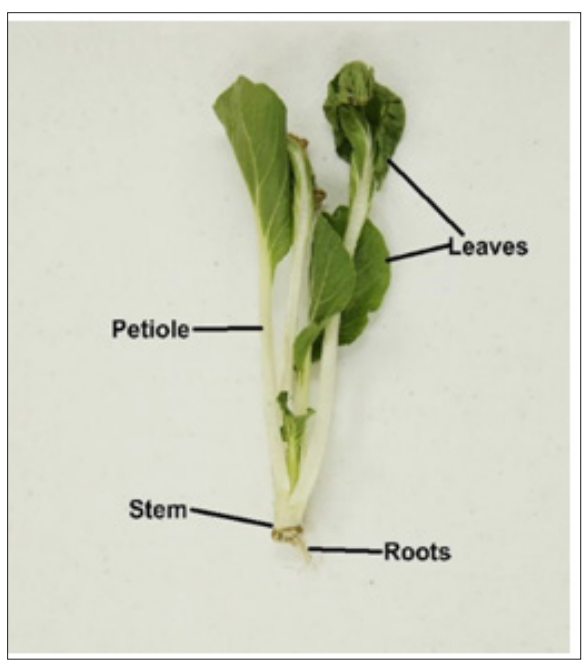

Figure 7: Full grown Pechay with its growth parts using upcycling of Pechay's Stem. 


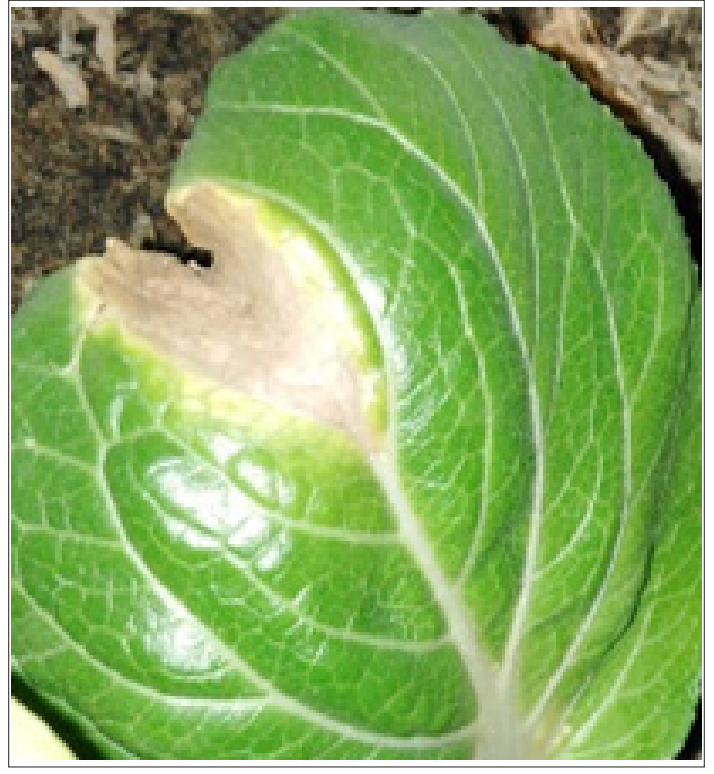

Figure 8: Dark brown becomes brittle. Suspected infection in a V shape.

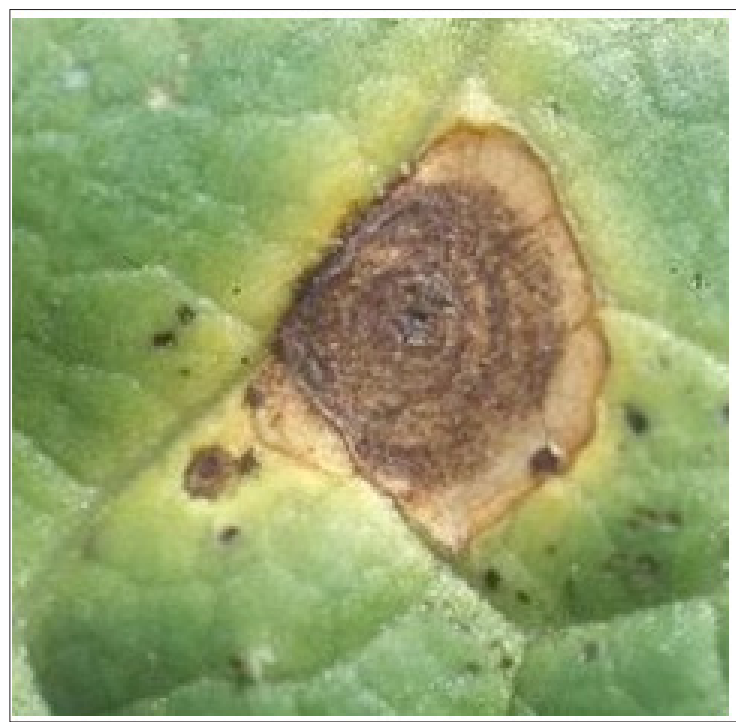

Figure 9: Infected leaf spotted brown.

Table 2: Tabulated data of pechay through seed planting.

\begin{tabular}{|c|c|c|c|}
\hline Groups & Number of Pechay Seed & Number of Pechay Seed Survived & Percent of Survival \\
\hline PA 12 & 20 & 18 & $90 \%$ \\
\hline HRDM 11 & 20 & 19 & $95 \%$ \\
\hline MM 13 & 20 & 20 & $100 \%$ \\
\hline ED 14 & 20 & 20 & $100 \%$ \\
\hline ECO 11 & 20 & 20 & $100 \%$ \\
\hline ECO 12 & 20 & 20 & $100 \%$ \\
\hline BAC 12 & 20 & 20 & $100 \%$ \\
\hline BAC 11 & 20 & 20 & $100 \%$ \\
\hline BEN 11 & 20 & 20 & $100 \%$ \\
\hline Total & 180 & 177 & $98.33 \%$ \\
\hline
\end{tabular}


Table 3: Comparison of number of upcycled pechay stem and pechay seed survived.

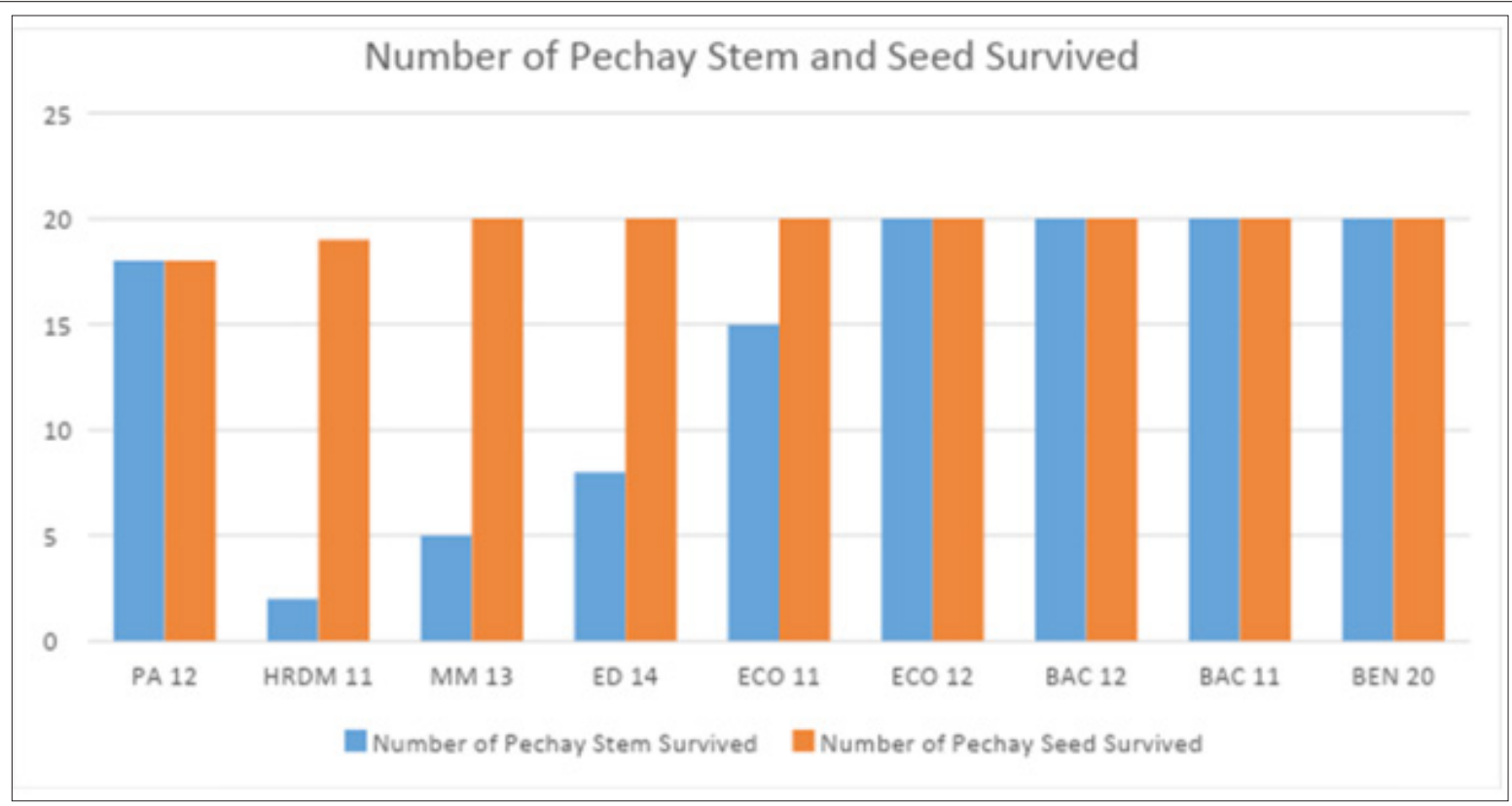

On Table 4, it explains that there were $90-100 \%$ survival rate of Pechay seeds and $75 \%$ survival rate for the Pechay stem. Pechay plants grow in the acclimatized temperature between $20^{\circ} \mathrm{C}$ to $34^{\circ} \mathrm{C}$ and watering were done once in the morning. However, $75 \%$ survival rate of Upcycled Pechay stem were affected by other uncontrolled Trichoderma is a genus of asexually reproducing fungi that is present in all types of soils. Trichoderma species have been recognized as antagonists of soil-borne and foliage pathogens and as efficient decomposers of cellulosic waste materials. Moreover, they have the ability to increase plant growth and induce plant resistance [6]. circumstances like drooping of leaves, pale color, too much rains.

Table 4: Comparison of percentage of survival growth of pechay stem and pechay seed.

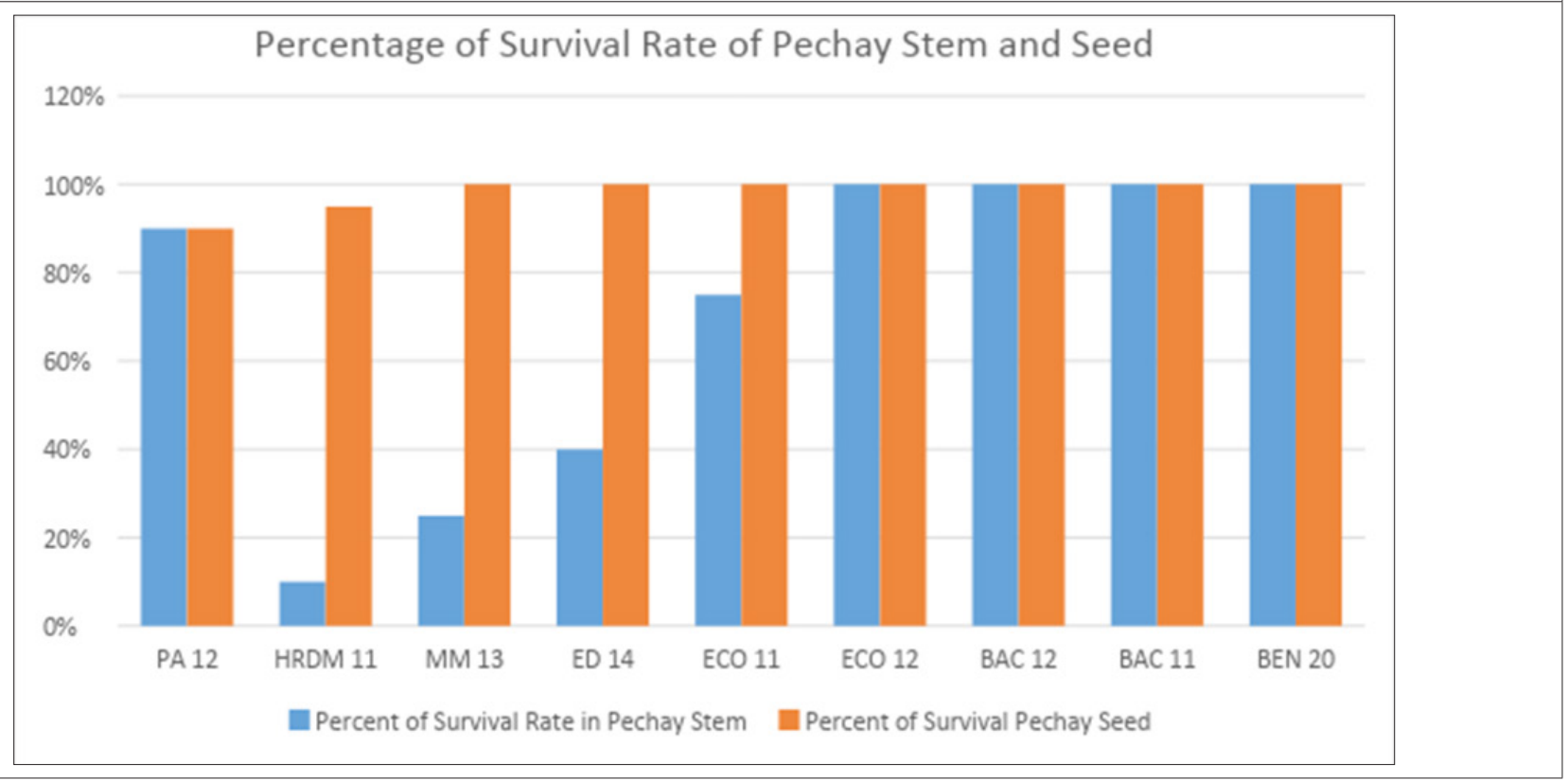

\section{Discussion}

Science and Technology Society course of Universidad de Manila came to an outcome based research output from Students of Public Administration (PA12), Education (Ed 14), Economics (Eco 11, Eco 12), Business Entrepreneurship (BEN 11), Human Resource Devel- opment Management ((HRDM 11), Bachelor and Arts and Communication (BAC11, BAC 12), Marketing and Management (MM13) in collaboration with the researchers came up with this experiments. Students brought in all the necessary material for planting, Pechay stems and seeds. Watering was done every morning. Based on the results and findings, Pechay seedlings grown and survived with 
98\% survival rate. However, the physiological growth characteristic of leaf buds was observed in the average between 3-days from the time it was planted. It took time to observed the growth characteristic of the Pechay seedlings. The weeks waiting period, Pechay grown from seedlings increased the height for about $76.2 \mathrm{~mm}$ and leaf grown wide of $38.1 \mathrm{~mm}$ from midrib to the leaf margin. On the study of Gonzales [7], wherein they observe the response of Brassica rapa on different levels of compost fertilizer, the sample cultivated in the garden soil with no input of fertilizer shows the least response amongst any other type of soil. Conclusively due to additional fertilizer and compost materials added to other experimental soil. On this study same results show that under a typical garden soil, Brassica rapa seeds flourish but within a minimal growth result. Upcycling is well integrated on this research study because we reused the stems of Brassica rapa without degrading the material it is made from [8]. The entire process requires the recreation of used materials or also known as waste materials to recreate and giving it another new life or function without having to spend much in getting new materials [9]. On this research study, we planted a used and is considered as waste stem of Brassica rapa and successfully produced a full-grown Brassica rapa as reflected on Figure7 without spending too much from it. This technique is not only for food consumption but likewise could become a potential source of income to most of those belonging to the urban poor sector. On this research study from the considered waste stems of Brassica rapa, we successfully reproduced a full grown Brassica rapa as shown on Table 4 and Figure 7, this is coherent on the definition of upcycling on the interview of kay Thornton \& Reiner Pilz [10] which explains that upcycling is a process of keeping its original form as much as possible and adding more value, whereas Braungart and McDonough [11] explains upcycling as the process that maintains or upgrades materials' value and quality in their second life, that is successfully exhibited on the results of this research study-that on the second life of Brassica rapa stems its value is much greater than it is considered as waste in the garbage bin. In addition to this, the high survival percentage of upcycling of Brassica rapa stems as shown on Table 4 challenges the scientists today to become more innovative and observant on the possible positive impact of upcycling to the increasing number of wastes in the environment. The invented products from upcycling would also pave way to increasing the ethical standards on scientists regarding waste managements. On this research study, it likewise challenges the scientists to research other plants that has the same positive response with upcycling.

With the rich biodiversity of the Philippines both flora and fauna, the upcycling process offers different raw materials to Filipinos, thus encouraging their creative and critical thinking in producing an innovative and inventive outcome [9], this encourages the Filipinos specifically on the urban poor to survive in this "survival of the fittest" type of environment that we have today through using their individual creative thinking skills. On the thesis study of [3] the most frequently mentioned perceived benefit of upcycling was 'economic benefit', true enough, the ones who will have a greater gain on upcycling process are those who sees its economic or mon- etary value. The successful result of this study as shown on Tables 3 and 4 only ensures the urban sector of the Filipino people that upcyling is not only for their own consumption but likewise it could be of great source of income for them with just limited space and low to none at all consumption of energy.

\section{Comparing Pechay seedlings to the upcycled Pechay stem.}

Growth characteristic of the upcycled Pechay was a lot better in terms of height and size of the leaf blade. Upcycled Pechay grown taller with the height of $254 \mathrm{~mm}$ and $76.6 \mathrm{~mm}$ size of the midrib in 2 weeks only with a $71 \%$ survival rate. The upcycled Pechay were harvested after 8 weeks and weighted to 500 grams. On the study of Bercero [12] on the growth performance of pechay on Household derived composts shows that a typical soil with no input of compost or fertilizer, Brassica rapa seeds survived but with the least response compared to other experimental soil with different types of compost embedded on the soil. Thus, Pechay or Brassica rapa survives even if the soil is not accompanied with rich compost soil substances.

\section{Pechay infection and unwanted visitors (Diamondback moth (DBM), Stray cats)}

However, there are other notable observed infection occurred on the Pechay leaves through marginal veins of the leaf blade eventually turn into yellow, movement usually in a V shaped suspected to be black rot (Xanthomonas campetris) due to warm, humid weather. Found in Figure 8 and 9. Black rot is a vascular disease in which pathogenic bacteria invade the xylem, colonise the mesophyll and ultimately spread throughout the plant. X. campestris pv. campestris survives in seeds, soil and especially, in plant debris and cruciferous weeds around the field, for long periods [13]. Diamondback moth, Plutella xylostella (L.) larva they thrive on leaves and finished of the entire peachy leaves at UDM.

The diamondback moth Plutella xylostella (Linnaeus) (Lepidoptera: Plutellidae) is one of the most destructive insect pests of cruciferous plants worldwide [14]. Diamondback moth, the life expectancy of an adult is 16 days for female and 12 days for male moths. Females lay their eggs up to 10 days and 95\% start laying on the day of emergence [15]. The preferred site for Diamondback moth oviposition on Brassica napus seems to be the lower first, second and third true leaves [15]. Unwanted visitor like the stray cat that litter in the Pechay plant box, Traces of cat feces were found on the soil and Pechay plants were uprooted. Pechay plants must be guarded and protected against cats and dog that they destroy of contaminate the vegetables as they can be a carrier of a food borne disease called Toxoplasmosis (Toxoplasma gondii), Harvested Pechay leaves has to be washed thoroughly with running water and to be cooked well, uncooked peachay is not recommended. Toxoplasmosis can be transmitted to humans by three principal routes. First, humans can eat raw or inadequately cooked infected meat or eat uncooked foods that have come in contact with contaminated meat. Second, humans can inadvertently ingest oocysts that cats have passed in their feces, either in a cat litter box or outdoors in soil (e.g., soil from gardening or unwashed fruits or vegetables) [16-19]. 


\section{Conclusion}

Based on the data gathered, upcycled Pechay stem cultivated in a loam soil in 8 weeks' observation period has a 71 percent survival rate at the UDM second floor building. Infection occurred on the Pechay leaves through marginal veins of the leaf blade eventually turn into yellow, movement usually in a V shape suspected to be black rot (Xanthomonas campetris). As of today we may neglect the economic importance of Brassica rapa, but its scientific contribution as it grows easily under normal condition, with or without fertilizers and compost embedded on the soil paves way for a fast and easy recording of data and results. It is suggested that vegetable cuttings for example Pechay (Brassica rapa) can be re planted in any recyclable container for urban gardening.

\section{Acknowledgement}

The researcher would like to extend a heartfelt gratitude to the Commission of Higher Education (CHED) for DARE TO Funding for providing UDM a Biodiversity Laboratory for the facility in data processing of the experiment, and to the UDM administrator for allowing the Science and Technology Society students and the researchers to conduct the experiments.

\section{References}

1. Kelly WT (1999) Specialty crops: Chinese cabbage and related orienta crops. Commercial vegetable production p. 8.

2. Renee Janet (2018) The nutrients of pechay.

3. Sung Kyungeun (2017) A review on upcycling: current body of literature, knowledge gaps and a way forward. Venice, Italy 17(4).

4. Vats Shameek (2016) Upcycling of waste.

5. Masabni, Joseph G (2010) Vegetable gardening in containers. Agri life Extensio Texas AM system, Texas, United States.
6. Cumagun CJR (2012) Managing plant diseases and promoting sustainability and productivity with trichoderma: The Philippine experience. J Agri Sci Tech 14: 699-714.

7. Gonzales MRL, Caralde RA, Aban MA (2014) Response of Brassica Napus. L to different levels of compost fertilizers. International Journal of Scientific Research and Publications 5(2).

8. Goldsmith B (2012) Trash or treasure? Upcycling becomes growing green trend.

9. Ali NS, Khairuddin NF, Zainal Abidin S (2013) Upcycling: Re-use and recreate functional interior space using waste materials. In DS 76: Proceedings of E\&PDE 2013, the $15^{\text {th }}$ International Conference on Engineering and Product Design Education, Dublin, Ireland, pp. 798803.

10. Kay T, Reiner pilz (1994).

11. Braungart M, McDonough W (2002) Cradle to cradle: Remaking the way we make things. New York, USA.

12. Bercero DM, Aranico EC, Tabaranza ACE, Amparado RF (2014) Growth performance of pechay (Brassica rapa) in household derived compost.

13. CABI (2015) Plutella xylostella.

14. Wei SJ, Shi BC, Gong YJ, Jin GH, Chen XX, et al. (2013) Genetic structure and demographic history reveal migration of the diamondback moth plutella xylostella (Lepidoptera: Plutellidae) from the southern to northern regions of China. PLoS One 8(4): e59654.

15. Silva R, Furlong MJ (2012) Diamondback moth oviposition: Effects of host plant and herbivory. Entomologia Experimentalis et Applicata 143(3): 218-30

16. Hussain MA, Stitt V, Szabo EA, Nelan B (2017) Toxoplasma gondii in the Food Supply. Pathogens 6(2): 21

17. Brown A (2012) Reduce reuse upcycle.

18. Singh D, Raghavendra BT, Singh Rathaur P, H Singh, Raghuwanshi R, et al. (2014) Detection of black rot disease causing pathogen Xanthomonas campestris pv. campestris by bio-PCR from seeds and plant parts of cole crops. Seed Sci \& Technol 42(1): 36-46.

19. WtERT "Waste-to-Energy Research and Technology Council". 